\title{
Tahminleme Tekniklerinin Bulanık Esnek Kümeler Üzerinde Birleştirilmesi: BIST 100 Uygulaması ${ }^{1}$ \\ Buğra BAĞCI ${ }^{2}$ \\ Ömür DEMIRER ${ }^{3}$
}

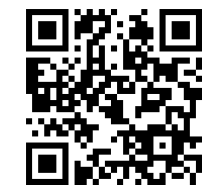

\begin{tabular}{ccc}
\hline $\begin{array}{c}\text { Geliş Tarihi//Received } \\
\text { 24/10/2019 }\end{array}$ & $\begin{array}{c}\text { Kabul Tarihi/ Accepted } \\
01 / 12 / 2020\end{array}$ & $\begin{array}{c}\text { Yayın Tarihi/Published } \\
15 / 01 / 2021\end{array}$ \\
\hline Citation/Atıf: Bağcl, B.. ve Demirer, Ö., (2021), Tahminleme Tekniklerinin Bulanık Esnek \\
Kümeler Üzerinde Birleştirilmesi: BIST 100 Uygulamasl, Atatürk Üniversitesi İktisadi ve İdari \\
Bilimler Dergisi, 35(1): Sayfa: 21-43, https.//doi.org/10.16951/atauniiibd.637554 \\
\hline
\end{tabular}

Öz: Gelecekteki belirsizlik insanoğlunu tarih boyunca korkutmuş ve insanoğlu da bu duruma karşılık, belirsizliği azaltmak veya onu ortadan kaldırabilmek için faklı yöntemler kullanmıştır. Gelecek olayların ve şartların daha önceden tahmin edilmesinin işletmecilikte olduğu gibi, makroekonomi, biyoloji, tıp, mühendislik ve sosyal bilimler alanlarında da çok önemli olduğu bilinmektedir. Gelecek bir zamanda gerçekleşecek senaryolara hazırlıklı olmak, planlar yapıp politikalar belirlemek ve nihayetinde kararlar almak ancak geleceğin iyi tahmin edilmesiyle mümkün olabilecektir. Bu şekilde yapılacak iyi bir tahmin geleceğin belirsizliğinden kaynaklanan endişeyi de azaltacaktır. Günümüzde, regresyon analizi, zaman serisi analizleri ve sezgisel yöntemler gibi birçok tahmin tekniği kullanılmaktadır. Fakat her bir yöntemin altyapısı ve algoritması birbirinden farklı olduğu için farklı sonuçlar üretmektedir. Tahmin sonuçları ile direkt olarak ilgilenen kişiler ve kurumlar da, en doğru sonucu veren analiz tekniğini bilmek istemektedirler. Çünkü gelecekteki olayların doğru tahmini, yoğun rekabet ortamında ilgililere üstünlük sağlayabilecektir. Buradan hareketle bu çalışmada farklı tahmin teknikleri, kurulan bir bulanık esnek küme üzerinde birleştirilmiş ve tek bir çıktı ile tahmin değeri elde edilmiştir. Analizlerde BIST 100 endeksi düzey değerleri ve bu değişken üzerinde etkisi olduğu düşünülen değişkenlere (enflasyon oranı, döviz kuru, altın fiyatları, mevduat faiz oranı, para arzı, iç borç stoğu, cari işlemler dengesi, kredi hacmi, petrol fiyatları, dıș ticaret dengesi ve sanayi üretim endeksi) ilişkin gerçek veriler kullanılmıştır. Oluşturulan bu veri seti gerek tek, gerekse çok boyutlu olarak çalışan farklı tahmin yöntemleri (ARIMA, çok değişkenli regresyon analizi, yapay sinir ağları ve üssel düzeltme) ile analiz edilmiş ve elde edilen sonuçlar bulanık esnek küme üzerinde birleștirilmiștir. Her bir yöntem ve kombin modelin başarısı hata terimleri ile ölçülmüs ve bu ölçüm en başarılı modelin kombin model olduğunu göstermiştir.

Anahtar Kelimeler: Tahminleme, Bulanık Esnek Kümeler, Kombin Modeller.

Combining Forecasting Techniques on Fuzzy Soft Sets: Application on XU 100

Abstract: The uncertainty of the future has frightened mankind throughout history, and mankind has used many techniques in response to this in order to reduce uncertainty or to remove

${ }^{I}$ Bu çalışma Buğra Bă̆cl tarafindan Dr. Öğr. Üyesi Ömür DEMIRER danışmanlı̆̆ında tamamlanan doktora tezi temel alınarak üretilmiștir.

${ }^{2}$ Dr. Öğretim Üyesi, Hitit Üniversitesi, İktisadi ve İdari Bilimler Fakültesi, Isşletme Bölümü. https://orcid.org/0000-0002-3268-3702

${ }^{3}$ Dr. Öğretim Üyesi, Hitit Üniversitesi, İktisadi ve İdari Bilimler Fakültesi, Uluslararası Ticaret ve Lojistik Yönetimi Bölümü. https://orcid.org/ 0000-0002-9502-9935 
it. It is well known that macroeconomics, biology, medicine, engineering and social sciences are very important as well as the way of forecasting future events and conditions is in business. Preparing for the script that will take place at an unprecedented time, making plans and determining policies and ultimately making decisions will only be possible with good predictions of the future. A good estimate of this will also reduce the anxiety of uncertainty. Today, there are many estimation techniques used, such as regression analysis, time series analyzes and heuristic methods. However, each method produces different results because its infrastructure and algorithm are different from each other. Those who are directly interested in forecasting results want to know the most accurate end result analysis technique. Because, rightly, the accurate prediction of future events will provide an advantage in the intense competition environment. In this thesis study prepared by moving from point to point, different estimation techniques are combined on a set of fuzzy soft sets and a prediction value is obtained with a single output. In the analysis, the actual data on variables (inflation rate, exchange rate, gold prices, deposit interest rate, money supply, domestic debt stock, curent account balance, credit volume, oil prices, foreign trade balance and industrial production index) that are thought to have an impact on the XU 100 levels are used. The generated data set was analyzed with a univariate or multivariate estimate analysis (ARIMA, multivariate regression analysis, artificial neural networks and exponential smoothing) and the obtained results were combined on a fuzzy set. The success of each method and combination model was measured by error terms and this measurement showed that the most successful model is the combined model.

Key Words: Forecasting, Fuzzy Soft Sets, Combine Models.

\section{Background}

\section{EXTENDED SUMMARY}

The decisions that people have to make in daily life are of great importance due to their future effects. Therefore, all individuals and institutions that are obliged to make decisions have to anticipate future events and produce adequate solutions within the framework of a good plan, at least in order to preserve or develop their current situation in the future. Here, the biggest purpose in predicting future uncertainty is to predict what will happen in the future, determine policies, prepare and plan accordingly.

After the Second World War, mathematicians, statisticians and economists tried to develop estimation methods and tried to overcome the uncertainties in many fields by using scientific techniques. Today, many quantitative techniques are used, especially trying to determine the course of time series. However, different techniques give more successful results according to some data structures. Researchers focused on obtaining the best prediction result have two different views. The first is to use the result of the technique with the lowest error rate. The second is to use a new result from the combination of all techniques. This second point of view is also valid in our study. In the light of this written information, the problem of examining the success rate of new results is focused on by combining the results produced by different estimation techniques on fuzzy soft sets.

\section{Purpose}

The main purpose of the study is to combine different estimation techniques with specific algorithms and produce more successful results. From 
this point of view, our study is to produce estimates with lower error rates than the individual error rates of the techniques by combining the results obtained from different time series estimation techniques on fuzzy soft sets.

\section{Method}

In the study, the closing price of the XU100 is estimated by both univariate and multivariate time series analyzes. These techniques are regression analysis, exponential smoothing model, artificial neural networks and ARIMA models. The estimation results obtained afterwards are used as data, and these data are combined over fuzzy soft sets.

\section{Findings}

In our study, a real time series are taken into consideration and this data is estimated with forecasting techniques with different working principles and backgrounds. According to the first findings, the individual method that best predicts the data set is the ARIMA model, followed by exponential smoothing, artificial neural networks and regression analysis. The estimation results obtained are considered as a set element on fuzzy soft sets. Each element is compared with the actual data and an accuracy value is determined. This determined accuracy value shows the membership degree of the element to the set. The estimation results of the combined model are produced by using the membership degrees of each element. When new estimation results are produced by combining the results on fuzzy soft sets, it is seen that the lowest error rate belongs to the combined results.

\section{Conclusions}

In our study, new estimation results are produced on fuzzy soft sets by using individual estimation techniques with different algorithms. In fact, estimation techniques are combined on fuzzy soft sets. When the results are compared with the error rates, it is seen that the combined model is more successful than individual prediction models. As a result, it is shown that univariate and multivariate time series estimation methods can be combined on fuzzy soft sets and successful results can be obtained.

\section{Giriş}

Gelecekteki belirsizlik insanoğlunu tarih boyunca korkutmuş ve insanoğlu da bu duruma karşılık, belirsizliği azaltmak veya onu ortadan kaldırabilmek için birçok teknik kullanmıştır. Falcıların, kâhinlerin kullandıkları bilimsel olmayan yöntemlerle geleceğin belirsizliğini aydınlatmaya çalışmaları, derebeyi, kral, imparator gibi kişilerin de yine yanlarında bilimsel olmayan yöntemlerle geleceği tahmin etmeye çalışan kişilerin bulunması, özellikle birçok insanın sorumluluğunu taşıyan yöneticilerde, gelecek endişesinin hangi boyutta olduğunu göstermektedir (Orhunbilge, 2002: 11). Bunun yanında, insanların günlük hayatta vermek zorunda oldukları kararlar da geleceğe yönelik etkilerinden dolayı büyük önem arz etmektedir. Dolayısıyla karar verme zorunluluğunda olan tüm kişi ve kurumlar, gelecekte en azından mevcut 
durumlarını korumak veya daha da geliştirebilmek adına gelecekteki olayları kestirmek ve iyi bir plan çerçevesinde uygun çözümler üretmek zorundadır. İşte, gelecekteki belirsizliğin tahmin edilmesindeki en büyük amaç, gelecekte ne olacağını kestirmek ve ona uygun politikalar belirleyip, hazırlık ve planlamalar yapmaktır. Bu bağlamda çalışmanın genel çerçevesini oluşturan tahmin kavramı aşağıdaki şekilde tanımlanabilir.

Tahmin, herhangi bir olayın geçmişten bugüne değerlerini ve seyrini inceleyerek, belirli varsayımlar altında, gelecekte ne durumda olabileceğini belirlemeye yönelik uğraşların tümüdür. Tahminin amacı ise, kişilerin ve kurumların gelecekte karşılaşabilecekleri durumları önceden kestirmek, çeşitli verileri ve teknikleri kullanarak önceden önlemler alınmasını sağlamak şeklinde açıklanmaktadır (Kayım, 1985: 1).

Gelecek olayların ve şartların daha önceden tahmin edilmesinin işletmecilikte olduğu gibi, makroekonomi, biyoloji, tıp, mühendislik ve diğer sosyal bilimler alanlarında da çok önemli olduğu bilinmektedir. Henüz gelmemiş bir zamanda gerçekleşecek senaryolara hazırlıklı olmak, planlar yapıp politikalar belirlemek ve nihayetinde kararlar almak ancak geleceğin iyi tahmin edilmesiyle mümkün olacaktır. Bu şekilde yapılacak iyi bir tahmin, geleceğin belirsizliğinden kaynaklanan endişeyi de azaltacaktır (Orhunbilge, 1999: 1).

İkinci dünya savaşından sonra matematikçi, istatistikçi ve ekonomistler tahmin yöntemleri geliştirmeye çalışmışlar ve birçok alandaki belirsizliklerin üstesinden bilimsel teknikler kullanarak gelme çabasında olmuşlardır (Orhunbilge, 2002: 12).

Her bir tahmin yönteminin problemi ele alış tarzları birbirlerinden farklı olması nedeniyle takip ettikleri algoritmalar ve çözüm yolları da birbirlerinden farklılaşmaktadır. Çoklu regresyon analizlerinde, tahmin edilecek bağımlı değişkenin etkilendiği değişkenlerin de belirlenerek tahmin yapılması ve tüm değişkenler arasındaki ilişkinin bir matematiksel fonksiyon yoluyla ifade edilmesi gerekirken, tek değişkenli zaman serileri analizlerinde, tahmin edilecek değişkenin sadece geçmişteki aldığı değerler kullanılarak gelecek değeri tahmin edilmektedir. Çok değişkenli zaman serilerinde ise, tahmin edilecek olan değişkenin hem kendi geçmiş değerlerinden hem de onu etkileyebilecek değişkenlerin şimdiki ve geçmiş değerlerinden etkilendiği düşünülerek tahmin fonksiyonu oluşturulmaktadır. Bir başka açıdan, sezgisel teknikler ise daha çok kesin çözümler yerine farklı durumları taklit ederek çözüme yaklaşmayı hedeflemekte ve bu doğrultuda geliştirilen algoritmalarla tahminleri yapmaktadırlar.

Tüm bu altyapı ve varsayım farklılıkları göz önüne alındığında aynı veri setine, uygunluğuna göre farklı teknikler uygulanabilmekte ve farklı sonuçlar elde edilebilmektedir. Dolayısıyla hangi tekniğin daha kullanışlı olduğu veya hangi tekniğin kullanılacağı sorunu ortaya çıkmaktadır. Ancak bu konuda fikir birliği oluşturabilecek herhangi bir gelişme sağlanamamıştır. Bu anlamda, veri setine ve probleme göre değişmek üzere, çok basit bir altyapıya sahip tekniğin 
çok daha kompleks yapılı bir teknikten daha doğru sonuçlar verebildiği de görülmektedir.

İşte tüm bu yazılanlar 1şı̆̆gnda çalışmamızda, öncelikle tahmin üzerine çalışma yapılması düşünülmüş ve bu düşünceyle teknikleri belli bir ayrıma tabi tutup herhangi biriyle sonuca ulaşmak yerine, tekniklerin birleştirilmesi ve uygun bir kombin yapılarak nihayetinde tekniklerin farklılıklarından yararlanmak amacıyla karma modeller kullanılmıştır. Birçok farklı şekilde birleştirmeler yapılabilmesine karşın, günümüzde yaygın olarak kullanılan bulanık kümelere dayanan bulanık esnek kümeler üzerinde birleştirmenin yapılabileceği ve literatürde daha önce hiç karşılaşılmayan çok boyutlu zaman serilerinin de bulanık esnek kümeler üzerinde birleştirilebileceği çalışmamızın temel varsayımıdır.

Çalışmamızın uygulama bölümü açısından bakıldığında, Borsa İstanbul 100 endeksi düzey değerleri üzerinde etkili olduğu düşünülen ve literatürde parçalar halinde kullanılan tüm değişkenler modellere dahil edilmiş ve gerçek veriler kullanılmıştır. Borsanın düzey değerleri de, kurulan modeller ve farklı tahminleme yöntemleriyle tahmin edilmiş ve sonunda tahmin sonuçları bulanık esnek kümeler üzerinde birleştirilmiştir.

Bütün bu açılamalardan sonra, bu çalışmanın ana amacı, literatürde yaygın olarak kullanılan farklı tahminleme yöntemleri ile yapılan analizlerden elde edilen sonuçların birleştirilmesi ve dolayısıyla tekniklerin farklılıklarından yaralanarak daha doğru bir tahmin yapılmasını sağlamak şeklinde açılanabilir.

Tüm bunlar göz önüne alındığında, tahminleme tekniklerine ait literatürde kullanılan analiz tekniklerinden herhangi birini seçmek ve onun sonucuna göre politikalar belirleyip kararlar almak yerine, tekniklerin farklılıklarından faydalanmak, mümkün olduğu kadar eksik yönlerinden kaçınmak, altyapı ve algoritmaları farklı olan teknikleri bir kümede birleştirmek, kombin modeller yaklaşımında ana hedef olmuştur. Bunun yanında, yapılan birleştirmenin teoride kalmayarak günlük hayatta kişilere ve işletmelere yol göstermesi ve kullanılması amacının güdülmesiyle o tabanda bir birleştirme yönteminin uygulanmasının çalışmaya literatürde bir kabul edilirlik ve güncellik katacă̆ 1 da düşünülmektedir. Ayrıca çalışma, karma tahmin yöntemi olarak tanıtılan bulanık esnek küme tabanlı yaklaşımla çok boyutlu zaman serilerinin ve sezgisel bir tahmin tekniğinin de ilk kez kullanılması nedeniyle özgün değer taşımaktadır. Böylece elde edilen sonuçların hem bilim, hem sektör, hem de günlük yaşam açısından kıymetli olduğu söylenebilir.

\section{Teorik Çerçeve ve Literatür Taraması}

\subsection{Bulanık Kümeler}

Bulanık kümeler teorisi, ilk defa 1965 yılında Lotfi A. Zadeh tarafindan Information and Control isimli dergide yayınlanan "Fuzzy Sets" başlıklı makale ile ortaya atılmıştır. Zadeh bu makalesinde insan düşünce yapısının bulanık 
olduğundan ve bu düşüncelerin açıklanmasında 0-1 iki değerli mantığın yetersiz kalacağından bahsetmiştir (Zadeh, 1965).

Matematiksel modelleme için bir yol olan bulanık mantık, sözel belirsizliklerin ve düşüncelerin modellenmesinde kullanılmaktadır. Aslında bulanık mantık düşünme, değerlendirme ve karar verme süreçlerinin adım adım ifade edilmesini săglamaktadır. Tabi ki, bulanık mantığın işlevleri de sınırlıdır. İnsan yaratıcılı̆̆ının tüm kapsamı bulanık mantık ile modellenememektedir (Altrock, 1995: 10).

Yaklaşık karar verme prensibi ile ilişkili olan bulanık mantıkta kesin yargılarla karar verme söz konusu değildir. Yaklaşıklık kavramı, sağduyu ile verilen kararların temelini oluşturması sebebiyle, bulanık mantığa ayrı bir önem kazandırmaktadır (Öztürk, 2011: 8).

Bulanık mantıkta temel araç olarak bulanık küme teorisi kullanılmaktadır. Bulanık mantığa ait olan temel matematiksel elemanlar, sonsuz değerli mantıktan hareketle geliştirilmiştir. Bulanık mantık, bulanık sayılar ve bulanık kümelerin sonsuz değerli mantığa eklenmesi ile açıllanabilmektedir (Bojadziev, 2007: 43).

Bulanık mantıkta çok kullanılan terimlerden bir tanesi de belirsizliktir. Belirsizlik kavramının genel kabul gören bir tanımı bulunmamaktadır. "Belirsizlik" ifadesi, içerisinde kesinlik bulunmayan bazı durumlarda kullanılan veriyi tanımlamak için kullanılmaktadır.

Yapılan pek çok çalışmada belirsizliğin, işlenmesi ve anlamlı sonuçlar elde edilebilmesi için olasılık teorisi kullanılmıștır. Sonuçların rastgele ortaya çıkması ve kesin bir doğrulukla önceden tahmin yapılamıyor olması olasılığın en önemli özelliğidir. Fakat uygulamada belirsizliklerin tamamının rastgele karakterli olduğu söylenemez. İşte, karakteri rastgele olmayan ve özellikle içerisinde sözel belirsizlikler barındıran olaylar söz konusu olduğunda inceleme ve sonuç elde etmede istatistik ve olasılık teorisi gibi teknikler yetersiz kalmaktadır (Şen, 2009: 12).

Olasılık kavramıyla, bir olayın meydana gelişindeki belirsizlik ifade edilmektedir. Bulanıklık ise, olayın meydana gelip gelmediğiyle değil, hangi noktaya kadar (dereceye kadar) gerçekleştiğini ölçmekle ilgilenmektedir. Bir olayın meydana gelip gelmemesi rastgeledir. Yani olayın gerçekleşeceği veya gerçekleşemeyeceği olasılık değeri ile ifade edilirken, olayın hangi noktaya kadar gerçekleştĭgi konusu ise bulanıklığın göstergesi olarak ifade edilir (Baykal ve Beyan, 2004: 311).

Bulanıklığın tespit edilebilen bir belirsizlik olması, olasılık ile bulanıklık arasındaki en büyük farklardandır.

Olasilık ile kurulan sistemlerde sonuç elde edilebilmesi için herhangi bir değişkene ihtiyaç duyulmamakta ve rastgele sonuç alınırken, bu durum bulanık temelli sistemlerde ise sonuç alınabilmesi için en az bir girdi değişkeni ve bir uzmanın tecrübelerine ihtiyaç duyulması şeklinde gerçekleşmektedir (Elmas, 2003: 38). 
Aralarında farklılıklar olmasının yanında bulanıklık ile olasılık değerlerinin $[0,1]$ kapalı aralığındaki belirsiz sayılardan oluşmaları da, bu iki kavram arasındaki benzerliklerdendir.

Tüm bu yazılanlar ışığında bulanık kümeler aşağıdaki şekilde tanımlanmaktadır.

Tanım: $U$ bir evrensel küme olmak üzere, $U$ kümesi üzerinde tanımlı bir bulanık $A$ kümesi, $U$ kümesinden $[0,1]$ aralığına tanımlı,

karakteristik fonksiyonu ile,

$$
\mu_{\tilde{A}}: U \rightarrow[0,1]
$$

$$
\tilde{A}=\left\{\left(\mu_{\tilde{A}}(x) / x\right): x \in U, \mu_{\tilde{A}}(x) \in[0,1]\right\}
$$

şeklinde ifade edilmektedir (Zadeh, 1965: 339).

Bulanık kümeler teorisinde bir $A$ bulanık kümesi $\tilde{A}$ şeklinde gösterilmektedir.

(1.1.1) gösteriminde, $\mu$ foksiyonuna $\tilde{A}$ bulanık kümesinin üyelik fonksiyonu veya karakteristik fonksiyonu denilmektedir. $\mu_{\tilde{A}}(x)$ değeri ise, $x$ elemanının $\tilde{A}$ bulanık kümesine ne kadar ait olduğunu gösteren ait olma derecesini ifade etmektedir. Burada üyelik derecesinin, elemanın kümeye ait olma olasılığı değil üyelik derecesini gösterdiği vurgulanmalıdır. Yani üyelik derecesi bir olasılık durumu vermemektedir. Bulanık kümelerde üyelik dereceleri, bulanık mantıkta önermelerin doğruluk değerine karşılık gelmektedir.

\subsection{Esnek Kümeler}

Esnek kümelere ait ilk çalışma Rus bilim adamı Dmitry Anatol'evich Molodtsov tarafından yapılmıştır. Molodtsov, 1999 yılında yayınladığı "Soft Set Theory-First Results" isimli çalışmasıyla bilim dünyasını esnek küme kavramıyla tanıştırmıştır. Molodtsov bu çalışmasında esnek kümelerde işlemler ve kümeler arasındaki ilişkilere değinmek yerine özellikle esnek analiz üzerine yoğunlaşıp limit, türev gibi temel analiz konularını esnek hale getirmeyi tercih etmiştir. Molodtsov 'un esnek kümelere yaklaşımı kendi ifadeleriyle şu şekildedir.

Tanım: $U$ bir evrensel küme, $P(U), U$ kümesinin alt kümelerinin kümesi (kuvvet kümesi), $E$ parametreler kümesi ve $A \subset E$ olsun.

olmak üzere,

$$
f_{A}: E \rightarrow P(U)
$$

$$
F_{A}=\left(f_{A}, E\right)=\left\{\left(x, f_{A}(x)\right): x \in E, f_{A}(x) \in P(U)\right\}
$$

şeklinde sıralı ikililerin bir kümesi ile tanımlanan $F_{A}$ kümesine esnek küme denir.

Yani bir esnek küme $U$ evrensel kümesinin alt kümelerinin parametrize edilmiş bir ailesidir.

Burada $U$ evrensel kümesine alternatiflerin kümesi, $E$ kümesine $U$ kümesinin elemanlarını niteleyen özelliklerden oluşan parametreler kümesi, $f_{A}$ fonksiyonuna $F_{A}$ esnek kümesinin yaklaşım fonksiyonu, $x \in E$ parametreleri ile ilişkili olan nesnelerin oluşturduğu $f_{A}(x)$ kümesine ise $x-$ yaklaşım değer kümesi veya $x$ - yaklaşım kümesi adı verilmektedir. 
Bir alternatifler (nesneler) kümesi üzerinde esnek kümenin tanımlanabilmesi için o alternatifleri karakterize eden özellikler (parametreler) ifade edilmelidir. Sıralı ikili şeklinde düşünüldüğünde, birinci bileşende özellik (parametre) ikinci bileşende ise o özelliğe sahip nesnelerin kümesi olacak şekilde ifade edilen sıralı ikililer yardımıyla esnek küme oluşturulur. Yani bu şekilde elde edilen sıralı ikililerin ailesine esnek küme denilmektedir. Başka bir ifadeyle, $U$ evrensel kümesinin alt kümelerinin parametrelerle ifade edilmiş (parametrize edilmiş) bir koleksiyonuna (ailesine) esnek küme denir (Molodtsov, 1999: 20).

Esnek küme teorisinde yaklaşım kavramı temel alınmaktadır. $x_{1}, x_{2} \in E$ için $f_{A}\left(x_{1}\right) \subset f_{A}\left(x_{2}\right)$ ise $x_{1}$ parametresinin yaklaşım değeri $x_{2}$ parametresinin yaklaşım değerinden küçüktür. Dolayısıyla $x_{2}$ parametresi $U$ kümesi üzerinde $x_{1}$ parametresinden daha fazla elemanla ilişkilidir şeklinde yorumlanmaktadır (Enginoğlu, 2008: 30).

Esnek kümeler, elemanlarının listelenmesi ile gösterilebilir.

Örneğin; $U=\left\{u_{1}, u_{2}, u_{3}, u_{4}\right\}$ alternatifler (nesneler) kümesi, $E=\left\{x_{1}, x_{2}, x_{3}, x_{4}, x_{5}\right\}$ parametreler kümesi ve $A=\left\{x_{1}, x_{2}, x_{4}\right\} \subset E$ olmak üzere,

olsun.

$$
f_{A}\left(x_{1}\right)=\left\{u_{1}, u_{3}\right\}, \quad f_{A}\left(x_{2}\right)=\varnothing, \quad f_{A}\left(x_{4}\right)=\left\{u_{2}, u_{4}\right\}
$$

Bu durumda $F_{A}$ esnek kümesi;

$$
\begin{gathered}
F_{A}=\left\{\left(x_{1},\left\{u_{1}, u_{3}\right\}\right),\left(x_{2}, \varnothing\right),\left(x_{4},\left\{u_{2}, u_{4}\right\}\right)\right\} \\
F_{A}=\left\{\left(x_{1},\left\{u_{1}, u_{3}\right\}\right),\left(x_{4},\left\{u_{2}, u_{4}\right\}\right)\right\}
\end{gathered}
$$

şeklinde ifade edilebilir.

Esnek kümelerle birlikte kullanılan verilerin daha rahat görülebilmesi ve özellikle bilgisayar uygulamalarının daha kolay olması açısından tablo yöntemi kullanılmaktadır.

$U$ bir evrensel küme, $E$ parametreler kümesi ve $A \subset E$ olsun. $U$ evrensel kümesi üzerinde tanımlanan bir $F_{A}$ esnek kümesinin bilgi tablosu; $i=1,2,3, \ldots, m, j=1,2,3, \ldots, n$ ve $U=\left\{u_{1}, u_{2}, u_{3}, \ldots, u_{m}\right\}$ evrensel küme ve $E=\left\{x_{1}, x_{2}, x_{3}, \ldots, x_{n}\right\}$ parametreler kümesi olmak üzere;

$$
\begin{array}{r}
\rho_{f_{A}}: U x E \rightarrow\{0,1\} \\
\left(u_{i}, x_{j}\right) \rightarrow \rho_{f_{A}}\left(u_{i}, x_{j}\right)= \begin{cases}1, & u_{i} \in f_{A}\left(x_{j}\right) \\
0, & u_{i} \notin f_{A}\left(x_{j}\right)\end{cases}
\end{array}
$$

dönüşümü yardımıyla, 
Tablo 1.1. Esnek kümelerde bilgi tablosu

\begin{tabular}{|c|c|c|c|c|c|c|}
\hline $\boldsymbol{\rho}_{f_{A}}$ & $x_{1}$ & $x_{2}$ & . & . & . & $x_{n}$ \\
\hline$u_{1}$ & $\rho_{f_{A}}\left(u_{1}, x_{1}\right)$ & $\rho_{f_{A}}\left(u_{1}, x_{2}\right)$ & . & . & . & $\rho_{f_{A}}\left(u_{1}, x_{n}\right)$ \\
\hline$u_{2}$ & $\rho_{f_{A}}\left(u_{2}, x_{1}\right)$ & $\rho_{f_{A}}\left(u_{2}, x_{2}\right)$ & . & . & . & $\rho_{f_{A}}\left(u_{2}, x_{n}\right)$ \\
\hline . & . & . & . & . & . & . \\
\hline . & . & . & . & . & . & . \\
\hline - & . & . & . & . & ${ }^{\circ}$ & . \\
\hline$u_{m}$ & $\rho_{f_{A}}\left(u_{m}, x_{1}\right)$ & $\rho_{f_{A}}\left(u_{m}, x_{2}\right)$ & . & . & . & $\rho_{f_{A}}\left(u_{m}, x_{n}\right)$ \\
\hline
\end{tabular}

şeklinde yazılır (Maji vd., 2002: 1080).

\subsection{Bulanık Esnek Kümeler}

Maji ve arkadaşları 2001 yılında yayınladıkları "Fuzzy Soft Sets" isimli makalelerinde esnek küme kavramını bulanık alt kümelere uygulayarak bulanık esnek küme tanımını yapmışlardır.

Tanım: $U$ evrensel kümesi ve $E$ parametreler kümesi boştan farklı herhangi iki küme olsun. $U$ kümesi üzerinde tanımlanan bütün bulanık kümelerin kümesi $F(U)$ ve $A \subseteq E$ olmak üzere $U$ kümesi üzerinde tanımlanan bir $\Gamma_{A}$ bulanık esnek kümesi,

$$
\gamma_{A}(x)=\left\{\frac{\mu_{\gamma_{A}(x)}(u)}{u}: u \in U, \mu_{\gamma_{A}(x)}(u) \in[0,1]\right\}
$$

bulanık kümesi ile,

$$
\Gamma_{A}=\left\{\left(x, \gamma_{A}(x)\right): x \in E, \gamma_{A}(x) \in F(U)\right\}
$$

ve $\forall x \notin A$ için $\gamma_{A}(x)=\emptyset$

biçiminde tanımlanır.

Burada $U$ kümesi söz konusu alternatiflerin kümesini, $E$ kümesi alternatifleri niteleyen parametrelerin kümesini, $\gamma_{A}$ fonksiyonu $A$ bulanık esnek kümesinin yaklaşım fonksiyonunu göstermektedir. Ayrıca $\gamma_{A}(x)$ değerlerine de, $x \in E$ elemanının $x-$ yaklaşımı denir (Roy ve Maji, 2007: 414).

Bir alternatifler (nesneler) kümesi üzerinde bulanık esnek kümenin tanımlanabilmesi için o alternatifleri karakterize eden özellikler (parametreler) ifade edilmelidir. Sıralı ikili şeklinde düşünüldügünde, birinci bileşende özellik (parametre) ikinci bileşende ise o özelliğe belli bir üyelik derecesi ile sahip nesnelerin kümesi olacak şekilde ifade edilen sıralı ikililer yardımıyla bulanık esnek küme oluşturulur. Yani bu şekilde elde edilen sıralı ikililerin ailesine bulanık esnek küme denilmektedir. Başka bir ifadeyle, $U$ evrensel kümesinin bulanık alt kümelerinin parametrelerle ifade edilmiş (parametrize edilmiş) bir koleksiyonuna (ailesine) bulanık esnek küme denir. 
Tahminleme Tekniklerinin Bulanık Esnek Kümeler Üzerinde Birleştirilmesi: BIST 100 Uygulaması

Bulanık esnek kümeler, elemanlarının listelenmesi ile gösterilebilir.

Örneğin; $U=\left\{u_{1}, u_{2}, u_{3}, u_{4}\right\}$ alternatifler (nesneler) kümesi, $E=\left\{x_{1}, x_{2}, x_{3}, x_{4}, x_{5}\right\}$ parametreler kümesi ve $A=\left\{x_{1}, x_{2}, x_{4}\right\} \subset E$ olmak üzere,

olsun.

$$
\gamma_{A}\left(x_{1}\right)=\left\{\frac{0.3}{u_{1}}, \frac{1}{u_{3}}\right\}, \quad \gamma_{A}\left(x_{2}\right)=\emptyset, \quad \gamma_{A}\left(x_{4}\right)=\left\{\frac{0.9}{u_{2}}, \frac{0.2}{u_{4}}\right\}
$$

Bu durumda $\Gamma_{A}$ bulanık esnek kümesi;

$$
\begin{gathered}
\Gamma_{A}=\left\{\left(x_{1},\left\{\frac{0.3}{u_{1}}, \frac{1}{u_{3}}\right\}\right),\left(x_{2}, \emptyset\right),\left(x_{4},\left\{\frac{0.9}{u_{2}}, \frac{0.2}{u_{4}}\right\}\right)\right\} \\
\Gamma_{A}=\left\{\left(x_{1},\left\{\frac{0.3}{u_{1}}, \frac{1}{u_{3}}\right\}\right),\left(x_{4},\left\{\frac{0.9}{u_{2}}, \frac{0.2}{u_{4}}\right\}\right)\right\}
\end{gathered}
$$

şeklinde ifade edilebilir.

Bulanık esnek kümelerle birlikte kullanılan verilerin daha rahat görülebilmesi ve özellikle bilgisayar uygulamalarının daha kolay olması açısından da tablo yöntemi kullanılmaktadır.

$U=\left\{u_{1}, u_{2}, u_{3}, \ldots, u_{m}\right\}$ bir evrensel küme, $E=\left\{x_{1}, x_{2}, x_{3}, \ldots, x_{n}\right\}$ parametreler kümesi ve $A \subset E$ olsun. $U$ evrensel kümesi üzerinde tanımlanan bir $\Gamma_{A}$ bulanık esnek kümesinin bilgi tablosu; $i=1,2,3, \ldots, m$ ve $j=1,2,3, \ldots, n$ olmak üzere;

dönüşümü yardımıyla,

\begin{tabular}{|c|c|c|c|c|c|c|}
\hline$\mu_{\gamma_{A}}$ & $x_{1}$ & $x_{2}$ & . & . & . & $x_{n}$ \\
\hline$u_{1}$ & $\mu_{\gamma_{A}\left(x_{1}\right)}\left(u_{1}\right)$ & $\mu_{\gamma_{A}\left(x_{2}\right)}\left(u_{1}\right)$ & . & ${ }^{\circ}$ & $\cdot$ & $\mu_{\gamma_{A}\left(x_{n}\right)}\left(u_{1}\right)$ \\
\hline$u_{2}$ & $\mu_{\gamma_{A}\left(x_{1}\right)}\left(u_{2}\right)$ & $\mu_{\gamma_{A}\left(x_{2}\right)}\left(u_{2}\right)$ & . & $\cdot$ & $\cdot$ & $\mu_{\gamma_{A}\left(x_{n}\right)}\left(u_{2}\right)$ \\
\hline . & . & . & . & . & . & . \\
\hline . & . & . & . & . & . & . \\
\hline . & . & . & . & . & $\cdot$ & . \\
\hline$u_{m}$ & $\mu_{\gamma_{A}\left(x_{1}\right)}\left(u_{m}\right)$ & $\mu_{\gamma_{A}\left(x_{2}\right)}\left(u_{m}\right)$ & . & - & & $\mu_{\gamma_{A}\left(x_{n}\right)}\left(u_{m}\right)$ \\
\hline
\end{tabular}

$$
\mu_{\gamma_{A}}: U x E \rightarrow[0,1]
$$

Tablo 1.2. Bulanı esnek kümelerde bilgi tablosu

şeklinde yazılır. Burada $\mu_{\gamma_{A}}, \gamma_{A}$ bulanık kümesinin üyelik fonksiyonunu göstermektedir (Maji vd., 2002: 1080).

Eğer, $i=1,2,3, \ldots, m$ ve $j=1,2,3, \ldots, n$ olmak üzere $a_{i j}=\mu_{\gamma_{A}\left(x_{j}\right)}\left(u_{i}\right)$, ise $\Gamma_{A}$ bulanık esnek kümesi aşağıdaki gibi matris şeklinde de gösterilebilir (Çağman ve Enginoğlu, 2012: 111). 


$$
\left[a_{i j}\right]_{m x n}=\left[\begin{array}{cccccc}
x_{11} & x_{12} & \cdot & \cdot & \cdot & x_{1 n} \\
x_{21} & x_{22} & \cdot & \cdot & \cdot & x_{2 n} \\
\cdot & \cdot & \cdot & \cdot & \cdot & \cdot \\
\cdot & \cdot & \cdot & \cdot & \cdot & \cdot \\
\cdot & \cdot & \cdot & \cdot & \cdot & \cdot \\
x_{m 1} & x_{m 2} & \cdot & \cdot & \cdot & x_{m n}
\end{array}\right]
$$

Örnek: X işletmesi üretimde kullanmak üzere hammadde teminini 5 farklı tedarikçi firmadan sağlamaktadır. Ayrıca X işletmesi bu tedarikçilerin her birini rekabetçi önceliklerin göstergesi olan "hız, kalite, maliyet ve esneklik" şeklinde 4 özelliğe yani parametreye göre değerlendirmiştir.

$U=\left\{t_{1}, t_{2}, t_{3}, t_{4}, t_{5}\right\} \quad$ alternatif tedarikçilerin kümesi ve $E=\left\{x_{1}, x_{2}, x_{3}, x_{4}\right\}$ bu alternatif tedarikçileri niteleyen özellikler olsun. Burada, $x_{1}$, hammaddeyi hızlı tedarik etmeyi, $x_{2}$, hammaddeyi kaliteli olarak sağlamayı, $x_{3}$, hammaddeyi düşük maliyetle sağlamayı, $x_{4}$, tedarikçi işletmelerin esnekliğini ifade eden özellikler olduğunu varsayalım.

$\Gamma_{A}$ bulanık esnek kümesi bu işletmenin hammadde almayı planladığı tedarikçilerin uygunluğunu gösteren bir bulanık esnek küme şeklinde tanımlansin.

Buna göre uygun tedarikçiyi seçmek isteyen bu işletme için $\gamma$ yaklaşım fonksiyonu,

$$
\begin{gathered}
\gamma\left(x_{1}\right)=\left\{\frac{0.2}{t_{1}}, \frac{0.7}{t_{2}}\right\} \\
\gamma\left(x_{2}\right)=\left\{\frac{0.5}{t_{2}}, \frac{1}{t_{4}}, \frac{0.1}{t_{5}}\right\} \\
\gamma\left(x_{3}\right)=\emptyset \\
\gamma\left(x_{4}\right)=\left\{\frac{0.2}{t_{3}}, \frac{0.8}{t_{4}}, \frac{0.8}{t_{5}}\right\}
\end{gathered}
$$

şeklinde verilmiş olsun. Dolayısıyla $\Gamma_{A}$ bulanık esnek kümesi;

$$
\begin{gathered}
\Gamma_{A}=\left\{\left(x_{1},\left\{\frac{0.2}{t_{1}}, \frac{0.7}{t_{2}}\right\}\right),\left(x_{2},\left\{\frac{0.5}{t_{2}}, \frac{1}{t_{4}}, \frac{0.1}{t_{5}}\right\}\right),\left(x_{3}, \varnothing\right)\left(x_{4},\left\{\frac{0.2}{t_{3}}, \frac{0.8}{t_{4}}, \frac{0.8}{t_{5}}\right\}\right)\right\} \\
\Gamma_{A}=\left\{\left(x_{1},\left\{\frac{0.2}{t_{1}}, \frac{0.7}{t_{2}}\right\}\right),\left(x_{2},\left\{\frac{0.5}{t_{2}}, \frac{1}{t_{4}}, \frac{0.1}{t_{5}}\right\}\right),\left(x_{4},\left\{\frac{0.2}{t_{3}}, \frac{0.8}{t_{4}}, \frac{0.8}{t_{5}}\right\}\right)\right\}
\end{gathered}
$$

şeklinde oluşturulur. Daha açık şekilde yazılacak olursa;

$$
\Gamma_{A}=\left\{\left(\text { hızl },\left\{\frac{0.2}{t_{1}}, \frac{0.7}{t_{2}}\right\}\right),\left(\text { kaliteli },\left\{\frac{0.5}{t_{2}}, \frac{1}{t_{4}}, \frac{0.1}{t_{5}}\right\}\right),\left(\text { esnek },\left\{\frac{0.2}{t_{3}}, \frac{0.8}{t_{4}}, \frac{0.8}{t_{5}}\right\}\right)\right\}
$$

biçiminde de yazılabilir.

Burada düşük maliyet özelliği ile ilişkili olan tedarikçi olmadığı için oluşturulan bulanık esnek kümeye alınmamıştır. 
Tahminleme Tekniklerinin Bulanık Esnek Kümeler Üzerinde Birleştirilmesi: BIST 100 Uygulamast

$\mathrm{Bu}$ şekilde oluşturulan $\Gamma_{A}$ bulanık esnek kümesi aşağıdaki şekilde tablo yöntemiyle de ifade edilebilir.

$$
\rho_{f_{A}}: U x E \rightarrow[0,1]
$$

dönüşümü yardımıyla ( $i=1,2,3,4,5$ ve $j=1,2,3,4$ olmak üzere);

\begin{tabular}{ccccc}
\hline$\rho_{f_{A}}$ & hlz $\left(x_{1}\right)$ & kalite $\left(x_{2}\right)$ & maliyet $\left(x_{3}\right)$ & esneklik $\left(x_{4}\right)$ \\
\hline$t_{1}$ & 0.2 & 0 & 0 & 0 \\
\hline$t_{2}$ & 0.7 & 0.5 & 0 & 0 \\
\hline$t_{3}$ & 0 & 0 & 0 & 0.2 \\
\hline$t_{4}$ & 0 & 1 & 0 & 0.8 \\
\hline$t_{5}$ & 0 & 0.1 & 0 & 0.8 \\
\hline
\end{tabular}

veya

\begin{tabular}{cccc}
\hline$\rho_{f_{A}}$ & $h ı z\left(x_{1}\right)$ & kalite $\left(x_{2}\right)$ & esneklik $\left(x_{4}\right)$ \\
\hline$t_{1}$ & 0.2 & 0 & 0 \\
\hline$t_{2}$ & 0.7 & 0.5 & 0 \\
\hline$t_{3}$ & 0 & 0 & 0.2 \\
\hline$t_{4}$ & 0 & 1 & 0.8 \\
\hline$t_{5}$ & 0 & 0.1 & 0.8 \\
\hline
\end{tabular}

şeklinde yazılabilir.

\subsection{Karma Tahminleme Modelleri}

Tahmin tekniklerinin birbirlerinden farklı olduğunu düşünerek herhangi birini seçme ve o teknikle analizlere devam etme fikrinin yanında farklı tahmin tekniklerinin birleştirilebileceği düşüncesi de (Bates ve Granger, 1969; Dickinson, 1975; Makridakis vd., 1982; Deutsch vd., 1994) ortaya atılmıştır. Bu zamana kadar da başlıca bu sayılan eserler olmak üzere, birçok farklı çalışmada tahmin tekniklerinin farklı yollarla birleştirilmesi anlatılıp, uygulanmıştır.

Literatür incelendiğinde karma tahmin konseptinin ilk olarak (Bates ve Granger, 1969) ile başladığı görülmektedir. Bates ve Granger, bu çalışmalarında, en az iki tahmin yönteminin uygun lineer kombinlerini yapmış ve bu kombinler arasından daha iyi sonuçların alınabildiğini göstermişlerdir.

Sonrasında (Dickinson, 1975) çalışmalarında bağımsız tahmin tekniklerinin sonuçlarını minimum varyans kriterine göre birleştirmiş ve sonuçlarını incelemişlerdir. Bu çalışmada da kombin edilmiş tahmin sonuçlarının hata varyansının bağımsız tahminlerin hiçbirinin hata varyanslarından daha büyük olmadığını göstermişlerdir. 
(Makridakis ve ark., 1982) çalışmalarında, birden fazla modelden gelen tahminlerin kombinasyonunun daha iyi tahmin performansı sağladığı MCompetition yöntemini anlatmışlardır.

(Deutsch ve ark., 1994) kombin çalışmalarında, farklı regresyon tekniklerinden gelen değişken ağırlıklar kullanmışlardır. Fakat uygulamalarında değişken ağırlıklandırmanın her zaman sabit ağırlıklandırmadan daha iyi sonuç vermediğini gözlemlemişlerdir.

(Chan ve ark., 1999) çalışmalarında farklı ağırlıklandırma yöntemlerini kullanmıșlar ve bu ağırlıklandırmalar sonucundaki tahmin değerlerinin performanslarını incelemişlerdir. Çalışmalarında veri olarak Hong Kong'da faaliyet gösteren bir bankaya ait verileri kullanmışlardır.

(Zhong ve Xiao, 2002) çalışmalarında kaba kümeler teorisine dayanan bir ağırlıklandırma yöntemi önermişler ve kaba kümelerdeki karakteristik niteliklerin önem derecesini, ağılıklandırma ölçütü olarak kullanmışlardır.

(Prudencio ve Ludermir, 2006) çalışmalarında kombin modeller konusundaki çalışmalarında her bir bağımsız tahminin ağırlıklandırılmasında makine öğrenme yöntemini kullanmışlar ve çok katmanlı yapay sinir ağılarını da kullanarak doğrusal bir birleştirme yapmışlardır.

(Zhang, 2007) çalışmalarında, bağımsız tahmin yöntemlerinden elde edilen sonuçları ağırlıklandırmada GARCH modelini kullanmış ve elektronik ürünlerin satışlarının tahmin edilmesine uygulamıştır. Sonuçta, değişen ağırlıklandırma yönteminin, tek model seçimi veya sabit ağırlıklandırmaya dayanan birleştirme yaklaşımlarından daha iyi performans gösterdiğini anlatmıştır.

Tahmin sonuçlarının kombinasyonlarının yapılmasına ilişkin gelinen son noktada, artık tahminler, geliştirilen farklı kümeler üzerinde birleştirilmektedir. Örneğin, ilk kez (Xiao ve ark., 2009) tarafindan bulanık esnek kümeler üzerinde kombin işlemi yapılmıştır. İhracat verileri üzerinden yapılan işlemlerde başarılı sonuçlar elde edilmiştir. Fakat söz konusu çalışmada sadece zaman serisi analizlerinden birkaç teknik kullanılmış ve kullanılan zaman serisi tek boyutlu olarak ele alınmıştır.

\section{Veri Seti ve Yöntem}

\subsection{Veri Seti Ve Özellikleri}

Öncelikle çalışmamızda gerçek verilerle çalışılmış ve kullanılan veriler üç farklı kaynaktan elde edilmiştir. Bunlardan birincisi T.C. Merkez Bankası veri taban1, ikincisi Türkiye İstatistik Kurumu veri tabanı ve üçüncüsü ise Thomson Reuters programıdır. Yararlanılan her üç kaynağın da alanlarında en sağlıklı verileri sağlayan veri tabanları olması çalışmamızın analizleri ve sonuçlarının güvenilir olması açısından önemlidir.

Çalışmada kullanılan tüm değişkenlere ait veriler aylık periyotlarla elde edilmiştir. Farklı yayınlanma periyotlarına sahip değişkenlerin de var olması sebebiyle, analizlerde ortak periyoda sahip değişkenler kullanılmıştır. Ayrıca 
veriler, tüm değişkenlere ait ilk gözlemin var olduğu nokta tespit edilerek o noktadan başlatılmıştır ki bu tarih 01.01.2007'dir. Verilerin sonlandırıldığı tarih ise, 31.08.2017'dir.

Bağımsız değişkenlerin belirlenmesi aşamasında ise, literatür incelemesi yapıldığında (İltaş, 2015; Yaman, 2014; Aykut, 2015; Demir ve Yağcılar, 2009; Sevinç, 2014; Cihangir ve Kandemir, 2010) borsa düzey değerlerini etkilediği düşünülen ve adı geçen yayınlarda kullanılan değişkenler modele eklenmiştir.

Buradan hareketle Borsa İstanbul 100 endeksi düzey değerini etkilediği düşünülen bağımsız değișkenler; enflasyon, döviz kuru, altın fiyatları, dıș ticaret dengesi, para arzı, iç borç stoku, cari işlemler dengesi, kredi hacmi, reel efektif kur, petrol fiyatları, tasarruf mevduatı faiz oranı, sanayi üretim endeksi ve DİBS faiz oranı şeklinde belirlenmiştir.

\subsection{Yöntem}

Tahminlerin birleştirilmesi kavramına ait yukarıda verilen literatür taramasından hareketle, optimum ağırlıkları belirlemenin, bir vektör bulmak için karar verme problemi olduğu ve kombin modellerin tahminlerin hata kareleri toplamını minimize edebileceği söylenebilir.

Çalışmamıza konu olan model, her bir bağımsız tahmin yöntemiyle elde edilen sonuçları bulanık esnek kümenin bir elemanı olarak kabul etmekte ve bu tahminlerin gerçek değerlerden sapmasına göre bir üyelik fonksiyonu oluşturup, sonuç olarak gerçekleşen değere en yakın tahmin değerini elde etmeyi amaçlamaktadır.

Bütün bunlar göz önüne alınarak karma model aşağıdaki şekilde açıklanabilecektir.

Modelde; $y$, zaman serisinin gerçek değerlerinden oluşan vektör; $y_{t}$, $t=1,2, \ldots, n$ olmak üzere zamana göre gerçek değerleri; $c_{1}, c_{2}, c_{3}, \ldots c_{m} m$ farklı bağımsız tahmin değerini; $\lambda_{j},(j=1,2, \ldots, m)$ herbir bağımsız tahmin değerine ait ağıllık katsayılarını, $\widehat{y_{t}}$ ise $\mathrm{t}$ zamanındaki tahmin değerini göstermiş olsun.

Bu durumda, karma tahmin modeli aşağıdaki şekilde yazılabilir:

$$
\widehat{y_{t}}=\sum_{j=1}^{m} \lambda_{j} c_{j t}
$$

Burada açıkça görülmektedir ki $\lambda_{j},(j=1,2, \ldots, m)$ ağırlık katsayıları belirlenebildiği zaman tahmin değeri kolayca hesaplanabilmektedir.

Daha önce de belirtildiği üzere, bulanık esnek kümelere, elemanlar belli üyelik dereceleri ile üye olmaktadır. $\mathrm{Bu}$ modelde de, tahmin yöntemlerine atanacak üyelik dereceleri aşağıda tanımlanan (1.4.2) üyelik fonksiyonu ile sağlanacaktır.

$(F, A)$ bulanık esnek kümesi üzerinde tanımlı $\xi_{i j}(i=1,2,3, \ldots, n$; $j=1,2,3, \ldots m$ ) bulanık değişken olmak üzere buna bağlı olarak $\xi_{i j}$ değişkeninin üyelik fonksiyonu aşağıdaki şekilde yazılır. 


$$
f\left(\xi_{i j}\right)=\left(1-\frac{\left|\widehat{y_{l j}}-y_{i}\right|}{y_{i}}\right) \vee 0
$$

(1.4.2) eşitliğine göre her bir bulanık değişkene ait üyelik fonksiyonu, her bir zaman noktasındaki bağımsız tahminin tahmin doğruluğunu ifade etmektedir. Burada $\widehat{y_{l j}}$ her bir bağımsız tahminin tahmin değerini, $y_{i}$ ise her bir zaman noktasındaki gerçek değeri göstermektedir. Bazı ekstrem durumlarda, $\left(1-\frac{\left|\widehat{y_{l}}-y_{i}\right|}{y_{i}}\right)$ değeri negatif olabilir. Fakat üyelik fonksiyonunun negatif değer olmaması ve $[0,1]$ aralığında bir değer olması gerektiği düşünülerek formüle 0 (sıfır) minimum operatörü eklenmiştir. Dolayısıyla burada $f\left(\xi_{i j}\right) \in[0,1]$ olur. Bu şekilde $f\left(\xi_{i j}\right)$, tahmin değerinin gerçek değere ne kadar yakın olduğunun bir ölçüsü olmaktadır.

Her bir tahmin yönteminin her bir sonucuna atanan üyelik değerleri hesaplandıktan sonra ise, bir sonraki dönemi tahmin etmek için farklı yöntemlere atanacak üyelik derecesi aşağıdaki şekilde yazıldığı gibi ağırlıklı toplam yoluyla elde edilecektir.

$w_{j}(j=1,2, \ldots, m)$ bağımsız tahmin sonuçlarından elde edilen üyelik dereceleri toplamı olmak üzere $W=\left[w_{1}, w_{2}, w_{3}, \ldots, w_{m}\right]$ vektörü oluşturulur. Burada $w_{j}$ aşağıdaki şekilde hesaplanır:

$$
w_{j}=\sum_{i=1}^{n} f\left(\xi_{i j}\right)
$$

Ayrıca her bir bağımsız tahmin $c_{j}$ 'nin, ağırlık katsayısı $\lambda_{j}$ ise şu şekilde tanımlanmaktadır. $(j=1,2, \ldots, m)$ olmak üzere,

$$
\lambda_{j}=\frac{w_{j}}{\sum_{i=1}^{m} w_{i}}
$$

Model tanıtılmaya başlandığında yeni karma tahmin değerinin, $(t=1,2, \ldots, n)$ olmak üzere,

$$
\widehat{y_{t}}=\sum_{j=1}^{m} \lambda_{j} c_{j t}
$$

formülü ile hesaplanabileceği ve burada en önemli sorunun ağırlık katsayıları olan $\lambda_{j}$ değerlerinin belirlenmesi olduğu anlatılmıştı. Burada, (1.4.4) formülü ile $\lambda_{j}$ değerlerinin bulunabileceği eşitlik tanımlanmış ve sorun ortadan kalkmıştır.

Söz konusu karma model algoritma şeklinde aşağıdaki gibi ifade edilebilir.

Adım 1: $y_{t},(t=1,2, \ldots, n)$ zaman serisi şeklinde elde edilip düzenlenen veri seti olmak üzere bu değerlerden herbir bağımsız tahmin metodu ile $y_{t j},(t=1,2, \ldots, n, j=1,2, \ldots, m)$ tahminleri oluşturulur. 
Tahminleme Tekniklerinin Bulanık Esnek Kümeler Üzerinde Birleştirilmesi: BIST 100 Uygulaması

Adım 2:

$$
f\left(\xi_{i j}\right)=\left(1-\frac{\left|\widehat{y_{l j}}-y_{i}\right|}{y_{i}}\right) \vee 0
$$

formülü yardımıyla üyelik dereceleri hesaplanır.

Adım 3: $W=[0,0,0, \ldots, 0]$ başlangıç vektörü olmak üzere $w_{j}$,

$$
w_{j}=\sum_{i=1}^{n} f\left(\xi_{i j}\right)
$$

eşitliği ile hesaplanır.

Adım 4: Her bir ağırlık katsayısı $\lambda_{j}$,

formülü yardımıyla hesaplanır.

$$
\lambda_{j}=\frac{w_{j}}{\sum_{i=1}^{m} w_{i}}
$$

Adım 5: Son olarak karma tahmin sonucu

$$
\widehat{y_{t}}=\sum_{j=1}^{m} \lambda_{j} c_{j t}
$$

eşitliği ile elde edilir (Xiao vd., 2009: 326-333).

\section{Ampirik Bulgular}

Çalışmamızın ana amacı farklı tahmin tekniklerinin bulanık esnek kümeler üzerinde birleștirilmesi iken bu ana amaca götüren yolda, kullanılan her bir tahmin tekniği detaylı bir şekilde uygulanmış ve sonuçları paylaşılmıştır. Tabi ki her bir teknikten elde edilen sonuçlar bulanık esnek küme üzerinde yapılacak kombin için bir eleman vasfı görüp, bu anlamda kullanılmıştır.

Analiz aşamasında, oluşturulan veri setine uygun tahmin teknikleri araştırılmış ve sonuçta; çoklu doğrusal regresyon analizi, yapay sinir ağları, ARIMA ve üssel düzeltme yöntemleri belirlenmiştir. Burada belirlenen tekniklerin bir kısmının tek değişkenli, bir kısmının çok değişkenli, bir kısmının da sezgisel tabanlı olduğu görülmektedir.

Bu şekilde, kullanılan bağımlı değişkene ait gerçek değerler ile bu gerçek değerleri tahmin eden farklı tekniklere ilişkin sonuçlar aşağıdaki tabloda verilmiştir. 
Tablo 4.1. Tahmin tekniklerine ait tahmin değerleri ve gerçek değerler

\begin{tabular}{llllll}
\hline & $\begin{array}{l}\text { Gerçek } \\
\text { Değer }\end{array}$ & $\begin{array}{l}\text { Regresyon } \\
\text { Analizi }\end{array}$ & $\begin{array}{l}\text { Yapay Sinir } \\
\text { Ağlar1 }\end{array}$ & ARIMA & $\begin{array}{l}\text { Üssel } \\
\text { Düzeltme }\end{array}$ \\
\hline 1 & $48,579.20$ & $50,575.96$ & $43,164.26$ & & $48,579.20$ \\
\hline 2 & $52,404.43$ & $50,364.76$ & $46,953.03$ & $49,687.99$ & $48,680.38$ \\
\hline 3 & $51,166.77$ & $50,447.81$ & $53,504.56$ & $54,101.95$ & $53,244.40$ \\
\hline 4 & $56,658.60$ & $53,937.42$ & $54,736.21$ & $51,278.04$ & $56,777.76$ \\
\hline 5 & $56,334.83$ & $60,927.26$ & $58,011.27$ & $59,647.77$ & $57,777.67$ \\
\hline$\ldots$ & $\ldots$ & $\ldots$ & $\ldots$ & $\ldots$ & $\ldots$ \\
\hline 126 & $155,340.52$ & $140,563.92$ & $148,997.25$ & $151,456.43$ & $148,306.48$ \\
\hline 127 & $164,336.15$ & $158,979.00$ & $159,328.44$ & $157,338.72$ & $157,756.18$ \\
\hline 128 & $170,159.84$ & $140,882.61$ & $142,973.41$ & $167,034.08$ & $164,340.03$ \\
\hline
\end{tabular}

Bu veriler elde edildikten sonra, tahmin sonuçlarına göre bir bulanık esnek küme üzerinde kombinleme yapabilmek adına algoritma adımları izlenerek aşağıdaki tabloda yer alan üyelik değerleri hesaplanmıştır.

Tablo 4.2. Tahmin tekniklerine ait $f\left(\xi_{i j}\right)$ değerleri

\begin{tabular}{lllll}
\hline & $\begin{array}{l}\text { Regresyon } \\
\text { Analizi }\end{array}$ & $\begin{array}{l}\text { Yapay Sinir } \\
\text { Ăgları }\end{array}$ & ARIMA & $\begin{array}{l}\text { Üssel } \\
\text { Düzeltme }\end{array}$ \\
\hline $\mathbf{1}$ & 0,958896698 & 0,88853384 & - & 0,99999993 \\
\hline $\mathbf{2}$ & 0,96107823 & 0,895974443 & 0,948163924 & 0,92893635 \\
\hline $\mathbf{3}$ & 0,985948661 & 0,954310348 & 0,942634997 & 0,9593949 \\
\hline $\mathbf{4}$ & 0,951972422 & 0,966070726 & 0,905035503 & 0,99789679 \\
\hline $\mathbf{5}$ & 0,918479702 & 0,970241477 & 0,941191952 & 0,97438811 \\
\hline$\ldots$ & $\ldots$ & $\ldots$ & $\ldots$ & $\ldots$ \\
\hline $\mathbf{1 2 6}$ & 0,90487605 & 0,959165375 & 0,974996273 & 0,95471856 \\
\hline $\mathbf{1 2 7}$ & 0,967401277 & 0,969527645 & 0,957420023 & 0,9599603 \\
\hline $\mathbf{1 2 8}$ & 0,827942751 & 0,840230027 & 0,981630427 & 0,96579796 \\
\hline
\end{tabular}

Kombin model oluştururken kullanılacak $W$ vektörünün $w_{j}$ elemanları aşağıdaki gibi elde edilmiştir.

$$
\begin{aligned}
& w_{1}=\sum_{i=1}^{128} f\left(\xi_{i 1}\right)=117,138.456 \\
& w_{2}=\sum_{i=1}^{128} f\left(\xi_{i 2}\right)=122,157.978 \\
& w_{3}=\sum_{i=1}^{128} f\left(\xi_{i 3}\right)=120,864.811 \\
& w_{4}=\sum_{i=1}^{128} f\left(\xi_{i 4}\right)=121,789.413
\end{aligned}
$$


Tahminleme Tekniklerinin Bulanık Esnek Kümeler Üzerinde Birleştirilmesi: BIST 100 Uygulaması

Bu sonuçlarla oluşan $W$ vektörü, $W=[117,138.456 ; 122,157.978 ; 120,864.811 ; 121,789.413]$ şeklindedir.

Kombin model sonucuna ulaşmak için gereken ağırlıklar ise,

şeklinde elde hesaplanmıştır.

$$
\begin{aligned}
& \lambda_{1}=\frac{w_{1}}{\sum_{i=1}^{4} w_{i}}=0,243.050 \\
& \lambda_{2}=\frac{w_{2}}{\sum_{i=1}^{4} w_{i}}=0,253.465 \\
& \lambda_{3}=\frac{w_{3}}{\sum_{i=1}^{4} w_{i}}=0,250.782 \\
& \lambda_{4}=\frac{w_{4}}{\sum_{i=1}^{4} w_{i}}=0,252.701
\end{aligned}
$$

Kombin modelin tahmin fonksiyonunda yer alan değişkenler yerine yazıldığında aşağıdaki tahmin denklemleri elde edilmiştir.

$$
\begin{gathered}
\widehat{y_{1}}=\lambda_{1} c_{11}+\lambda_{2} c_{21}+\lambda_{3} c_{31}+\lambda_{4} c_{41}=35,509.20 \\
\widehat{y_{2}}=\lambda_{1} c_{12}+\lambda_{2} c_{22}+\lambda_{3} c_{32}+\lambda_{4} c_{42}=48,904.64 \\
\widehat{y_{3}}=\lambda_{1} c_{13}+\lambda_{2} c_{23}+\lambda_{3} c_{33}+\lambda_{4} c_{43}=52,845.69 \\
\widehat{y_{4}}=\lambda_{1} c_{14}+\lambda_{2} c_{24}+\lambda_{3} c_{34}+\lambda_{4} c_{44}=54,190.72 \\
\widehat{y_{5}}=\lambda_{1} c_{15}+\lambda_{2} c_{25}+\lambda_{3} c_{35}+\lambda_{4} c_{45}=59,071.38 \\
\widehat{\ldots . .} \\
\widehat{y_{126}}=\lambda_{1} c_{1,126}+\lambda_{2} c_{2,126}+\lambda_{3} c_{3,126}+\lambda_{4} c_{4,126}=147,389.68 \\
\widehat{y_{127}}=\lambda_{1} c_{1,127}+\lambda_{2} c_{2,127}+\lambda_{3} c_{3,127}+\lambda_{4} c_{4,127}=158,347.21 \\
=\lambda_{1} c_{1,128}+\lambda_{2} c_{2,128}+\lambda_{3} c_{3,128}+\lambda_{4} c_{4,128}=153,898.60
\end{gathered}
$$

Kombin model dahil olmak üzere bütün tahmin yöntemlerine ait tüm dönemlere ait tahmin değerleri toplu olarak aşağıdaki tabloda yer almaktadır.

Tablo 4.3. Tahmin teknikleri ve kombin modele ait tahmin değerleri ile gerçek değerler

\begin{tabular}{lllllll}
\hline & $\begin{array}{l}\text { Gerçek } \\
\text { Değer }\end{array}$ & $\begin{array}{l}\text { Regresyon } \\
\text { Analizi }\end{array}$ & $\begin{array}{l}\text { Yapay } \\
\text { Sinir } \\
\text { Ăgları }\end{array}$ & ARIMA & $\begin{array}{l}\text { Üssel } \\
\text { Düzeltme }\end{array}$ & $\begin{array}{l}\text { Kombin } \\
\text { Model }\end{array}$ \\
\hline $\mathbf{1}$ & $48,579.20$ & $50,575.96$ & $43,164.26$ & - & $48,579.20$ & $35,509.20$ \\
\hline $\mathbf{2}$ & $52,404.43$ & $50,364.76$ & $46,953.03$ & $49,687.99$ & $48,680.38$ & $48,904.64$ \\
\hline $\mathbf{3}$ & $51,166.77$ & $50,447.81$ & $53,504.56$ & $54,101.95$ & $53,244.40$ & $52,845.69$ \\
\hline $\mathbf{4}$ & $56,658.60$ & $53,937.42$ & $54,736.21$ & $51,278.04$ & $56,777.76$ & $54,190.72$ \\
\hline $\mathbf{5}$ & $56,334.83$ & $60,927.26$ & $58,011.27$ & $59,647.77$ & $57,777.67$ & $59,071.38$ \\
\hline$\ldots$ & $\ldots$ & $\ldots$ & $\ldots$ & $\ldots$ & $\ldots$ & $\ldots$ \\
\hline $\mathbf{1 2 6}$ & $155,340.52$ & $140,563.92$ & $148,997.25$ & $151,456.43$ & $148,306.48$ & $147,389.68$ \\
\hline $\mathbf{1 2 7}$ & $164,336.15$ & $158,979.00$ & $159,328.44$ & $157,338.72$ & $157,756.18$ & $158,347.21$ \\
\hline $\mathbf{1 2 8}$ & $170,159.84$ & $140,882.61$ & $142,973.41$ & $167,034.08$ & $164,340.03$ & $153,898.60$ \\
\hline & & & & & & \\
\hline
\end{tabular}

Tabloda yer alan sonuçlara göre hesaplanan, tahmin tekniklerine ait hata kareleri toplamları ise aşağıdaki tabloda verilmiştir. 
Tablo 4.4. Tahmin teknikleri ve kombin modele ait hata kareleri toplamlart

\begin{tabular}{ll}
\hline ANALIZ TEKNİĞ & HATA KARELERI TOPLAMI \\
\hline Regresyon Analizi & $12,026.538 .747 .51$ \\
\hline Yapay Sinir Ağları & $3,897.933 .991 .13$ \\
\hline ARIMA & $2,829.184 .831 .70$ \\
\hline Üssel Düzeltme & $3,167.669 .935 .01$ \\
\hline Kombin Model & $2,602.675 .232 .20$ \\
\hline
\end{tabular}

Bu tabloya göre hata kareleri toplamına göre en iyi sonucu kombin modelin verdiği, ARIMA sonucunun ikinci sırada yer aldığı ve devamında sırasıyla Üssel Düzeltme, Yapay Sinir Ağları ve Regresyon Analizlerinin geldiği görülmektedir.

Bir sonraki döneme ilişkin tahmin değerleri incelendiğinde ise,

Tablo 4.5. Tahmin teknikleri ve kombin modele ait gelecek dönem tahmin değerleri

\begin{tabular}{lllllll} 
& $\begin{array}{l}\text { Gerçek } \\
\text { Değer }\end{array}$ & $\begin{array}{l}\text { Regresyon } \\
\text { Analizi }\end{array}$ & $\begin{array}{l}\text { Yapay Sinir } \\
\text { Ağları }\end{array}$ & ARIMA & $\begin{array}{l}\text { Üssel } \\
\text { Düzeltme }\end{array}$ & $\begin{array}{l}\text { Kombin } \\
\text { Model }\end{array}$ \\
\hline $\mathbf{1 2 9}$ & $166,859.87$ & $148,918.95$ & $169,023.16$ & $171,442.16$ & $170,593.63$ & $165,140.29$ \\
\hline
\end{tabular}

tablosu elde edilmektedir.

$\mathrm{Bu}$ sonuçlara göre bir sonraki dönem için her bir tekniğin tahmin ettiği değer ile gerçek değer arasında oluşan farklar;

Tablo 4.6. Tahmin teknikleri ve kombin modele ait sonraki dönem gerçek değer ile tahmin değeri arasındaki fark

\begin{tabular}{ll}
\hline Regresyon Analizi & $-17,940.92$ \\
\hline Yapay Sinir Ağları Analizi & $2,163.18$ \\
\hline ARIMA & $4,582.29$ \\
\hline Üssel Düzeltme & $3,733.76$ \\
\hline Kombin Model & $-1,719.58$ \\
\hline
\end{tabular}

şeklindedir.

Buna göre bir sonraki dönemi tahmin etmede kombin modelin, diğer modellere göre daha başarılı olduğu görülmektedir.

Son olarak kurulan kombin model vasıtasıyla elde edilen tahmin değerleri ile bağımlı değişkene ait gerçek değerlerin zamana göre birlikte seyrini gösteren grafik çizilmiş ve aşağıdaki şekil 4.1 olarak paylaşılmıştır. 
Tahminleme Tekniklerinin Bulanık Esnek Kümeler Üzerinde Birleştirilmesi: BIST 100 Uygulamast

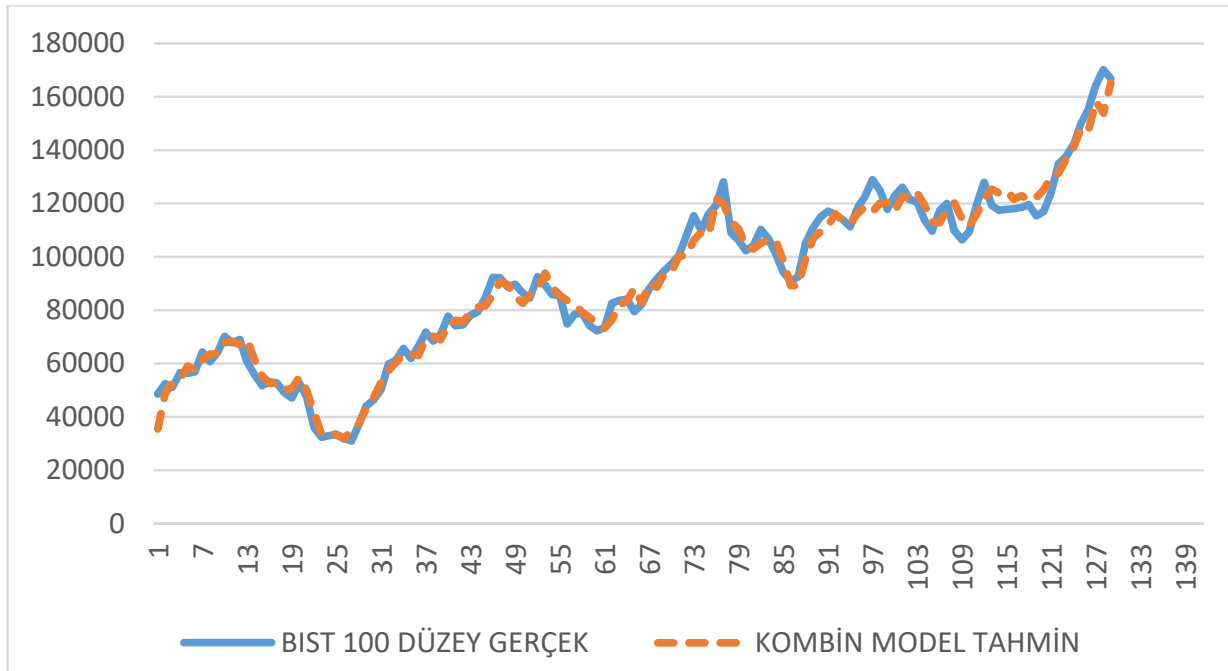

Şekil 4.1. Gerçek değer ile kombin model tahmin sonucunun zaman seyri

\section{Sonuç}

Çalışmanın ortaya çıkmasındaki temel problem cümlesi, daha doğru tahmin sonucunun elde edilmesi amacıyla herhangi bir yöntemin kullanılması yerine tüm tekniklerden elde edilecek kombin bir model yardımıyla her tekniğin katkısıyla daha doğru tahmin sonucuna ulaşılması yönünde idi. Sonuç olarak çalışmamızın amacına ulaştı̆̆ ve beklenen şekilde kombin modelin diğer tekniklere göre daha başarılı sonuçlar ürettiği görülmüştür. Bu sonuçtan hareketle aynı amaca hizmet eden farklı tekniklerin uygun matematiksel algoritmalarla birleştirilmesiyle başarılı sonuçların elde edilebileceği söylenebilir.

$\mathrm{Bu}$ şekilde kullanılan veri setinin geçek verilerden oluşması ve her bir yöntemin kendi altyapısına uygun şekilde tahmin yapmasına izin verilmesinin de elde edilen sonuçların doğruluğunda payı olduğu muhtemeldir. Yine birbirinden çok farklı altyapı ve algoritmalara sahip farklı tekniklerden elde edilen sonuçların kullanılması da kombin modelle elde edilen değerlerin doğruluğuna katkı sağlamaktadır. Bunlara ek olarak, bulanık esnek kümeler üzerinde birleştirme yapılırken kullanılan üyelik fonksiyonunun, tahmin tekniklerinin yaptığ tahminin doğruluğuna paralel olacak şekilde oluşturulması ve yapılan tahminin mümkün olduğu kadar doğru tarafını bulanık esnek kümeye dahil etmesi sebebiyle, son durumda elde edilen tahmin sonucunun başarısının arttığı ise göz ardı edilemeyecek bir gerçektir.

Sonuç olarak bu çalışmada tek değişkenli ve çok değişkenli farklı tahmin yöntemleri birleştirilerek kombin oluşturulmuş ve bulanık esnek kümeler tabanında oluşturulan bu kombin modelin başarısı ortaya çıkarılmıştır.

Elde edilen bu sonuçlar, literatürde bulanık esnek kümeler ile yapılmış farklı tek çalışma olan (Xiao vd., 2009) çalışmasına benzer şekilde kombin 
modelin başarısını göstermektedir. Yine sonuçlar, diğer kombin model çalışmalarından (Bates ve Granger, 1969; Dickinson, 1975; Makridakis vd., 1982) gibi çalışmaların sonuçları ile de paralellik göstermektedir.

Şüphesiz ki, tüm çalışmalarda amaç en iyi tahmini elde ederek, kişilerin ve kurumların geleceğin belirsizliğinden maksimum seviyede kaçınmasını sağlamaktır. Bu anlamda, tahmin sonuçlarıyla hareket eden ve politikalar belirleyenler için bu çalışmayla tek bir tahmin tekniği kullanmak yerine farklı tahmin tekniklerinden yapılan uygun kombinlerle daha doğru sonuçlara ulaş1labileceği gösterilmiştir.

Gelecek çalışmalar için öneriler getirilecek olursa, daha farklı tahmin teknikleri bu kümeye eklenerek veya birleştirmenin bulanık esnek kümeler üzerinde değil farklı kümeler üzerinde yapılması ile kombin modeller konseptine katkıda bulunulabileceği düşünülmektedir. Ayrıca birleştirme yapılırken kullanılan üyelik fonksiyonundan daha kullanışlı bir fonksiyonun yazılabilmesi de bu çalışmayı bir adım ileri taşıyabilecektir. Bununla birlikte yapılan birleştirme ile oluşturulan kümelerin veri yapısından nasıl etkilendiği ve nasıl tepkiler vereceği konusu da, bu çalışma hazırlandıktan sonra akla gelen bir başka soru olmuş ve burada paylaşılarak farklı çalışmaların ortaya çıkmasına zemin hazırlanmıştır.

\section{Kaynaklar}

Aykut, M.E. (2015). BIST-100 Endeksi İle Makroekonomik Değişkenler Arasındaki Nedensellik: 2005-2015 Yılları Arasinda Türkiye Uygulaması, (Doktora Tezi), Eskişehir: Anadolu Üniversitesi Sosyal Bilimler Enstitüsü.

Bates, J.M. ve Granger, C.W. (1969). The Combination Of Forecasts. Journal Of The Operational Research Society, 20(4), 451-468.

Baykal, N. ve Beyan, T. (2004). Bulanık Mantık Ilke Ve Temelleri, Ankara: Bıçaklar Kitabevi.

Bojadziev, G. (2007). Fuzzy Logic For Business, Finance, And Management, Vol. 23. World Scientific.

Cağman, N. ve Enginoğlu, S. (2012). Fuzzy Soft Matrix Theory And Its Application İn Decision Making. Iranian Journal of Fuzzy Systems, 9(1), 109-119.

Cihangir, M. ve Kandemir, T. (2010). Finansal Kriz Dönemlerinde Hisse Senetleri Getirilerini Etkileyen Makroekonomik Faktörlerin Arbitraj Fiyatlandırma Modeli Aracılığıyla Saptanmasına Yönelik Bir Çalışma (Kasım 2000 ve Şubat 2001 Finansal Krizleri Üzerine Değerlendirme ve Gözlemler), Süleyman Demirel Üniversitesi İktisadi ve İdari Bilimler Fakültesi Dergisi, 15(1), 257-296.

Demir, Y. ve Göçmenyağcılar, G. (2009). İMKB'de İşlem Gören Banka Hisse Senetlerinin Getirilerini Etkileyen Faktörlerin Arbitraj Fiyatlama Modeli İle Belirlenmesi. Uluslararası Alanya İşletme Fakültesi Dergisi, 1(2). 
Tahminleme Tekniklerinin Bulanık Esnek Kümeler Üzerinde Birleştirilmesi: BIST 100 Uygulamast

Deutsch, M., Granger, C.W. ve Teräsvirta, T. (1994). The Combination Of Forecasts Using Changing Weights. International Journal of Forecasting, 10(1), 47-57.

Dickinson, J.P. (1975). Some Comments On The Combination Of Forecasts. Journal of the Operational Research Society, 26(1), 205-210.

Elmas, Ç. (2003). Bulanık Mantık Denetleyiciler, Ankara: Seçkin Yayıncılık.

Enginoğlu, S. (2008). Soft Kümeler Ve Soft Karar Verme Metodlart, (Yüksek Lisans Tezi), Tokat: Gaziosmanpaşa Üniversitesi, Fen Bilimleri Enstitüsü.

İltaş, Y. (2015). Temel Makroekonomik Göstergelerin Isşletme Sermayesi Üzerine Etkisinin Incelenmesi: BIST'te Sektörler Arası Bir Karşılaştırma, (Doktora Tezi), Kayseri: Erciyes Üniversitesi Sosyal Bilimler Enstitüsü.

Kayım, H. (1985). Istatistiksel Ön Tahmin Yöntemleri, Ankara: Hacettepe Üniversitesi İktisadi Ve İdari Bilimler Fakültesi Yayınları.

Maji, P.K, Kumar, B., Ranjit. R. ve Akhil R. (2001). Fuzzy Soft Sets, Journal of Fuzzy Mathematics, 9(3), 589-602.

Maji, P.K., Roy, A.R. ve Biswas, R. (2002). An Application Of Soft Sets In A Decision Making Problem, Computers \& Mathematics With Applications, 44(8-9), 1077-1083.

Makridakis, S., Andersen, A., Carbone, R., Fildes, R., Hibon, M., Lewandowski, R., ... \& Winkler, R. (1982). The Accuracy Of Extrapolation (Time Series) Methods: Results Of A Forecasting Competition, Journal of Forecasting, 1(2), 111-153.

Molodtsov, D. (1999). Soft Set Theory-First Results, Computers \& Mathematics with Applications, 37(4-5), 19-31.

Orhunbilge, N. (1999). Zaman Serileri Analizi Tahmin Ve Fiyat Indeksleri, İstanbul: Tunç Matbaacilık.

Orhunbilge, N. (2002). Uygulamall Regresyon Ve Korelasyon Analizi, İstanbul: İ.Ü. Basım Ve Yayınevi.

Öztürk, B. (2011). Çok Kriterli Karar Verme Tekniklerinden Bulanık Topsıs Ve Bulanık Analitik Hiyerarşi Süreci, (Doktora Tezi), Bursa: Uludağ Üniversitesi Sosyal Bilimler Enstitüsü.

Ross, T.J. (2004). Fuzzy Logic With Engineering Applications, USA: John Wiley \& Sons Ltd.

Roy, A.R. ve Maji, P.K. (2007). A Fuzzy Soft Set Theoretic Approach To Decision Making Problems, Journal of Computational and Applied Mathematics, 203(2), 412-418.

Sevinç, E. (2014). Makroekonomik Değişkenlerin, BÌST-30 Endeksinde İşlem Gören Hisse Senedi Getirileri Üzerindeki Etkilerinin Arbitraj Fiyatlama Modeli Kullanarak Belirlenmesi, Istanbul University Journal of the School of Business Administration, 43(2).

Şen, Z. (2009). Bulanık Mantık Illkeleri Ve Modelleme, İstanbul: İstanbul Su Vakfi Yayınları. 
Xiao, Z., Gong, K. ve Zou, Y. (2009). A Combined Forecasting Approach Based On Fuzzy Soft Sets, Journal of Computational and Applied Mathematics, 228(1), 326-333.

Yaman, B.O. (2014). Hisse Senedi Endeks Getirileri Üzerinde Temel Makroekonomik Değişkenlerin Etkilerinin Ölçülmesi: Bazı Avrupa Birliği Üyesi Ülkeler Ile Türkiye Örneği, (Yüksek Lisans Tezi), Tokat: Gaziosmanpaşa Üniversitesi, Sosyal Bilimler Enstitüsü.

Zadeh, L.A. (1965). Fuzzy Sets, Information And Control, 8(3), 338-353.

Zadeh, L.A. (1995). Discussion: Probability Theory And Fuzzy Logic Are Complementary Rather Than Competitive. Technometrics, 37(3), 271276.

Zhang, H. ve Liu, D. (2006). Fuzzy Modeling And Fuzzy Control, Control Engineering Book Series, Boston: Brikhauser. 